\title{
Dietary Effects of Corn Oil, Oleic Acid, Perilla Oil, and Evening Primrose Oil on Plasma and Hepatic Lipid Level and Atherosclerosis in Japanese Quail
}

\author{
Al Muktafi SADI1), Takayoshi TODA ${ }^{1)}$, Hirosuke OKU2), and Seitetsu HOKAMA ${ }^{1)}$ \\ 1)Department of Clinical Laboratory Medicine, School of Medicine and ${ }^{2)}$ Department of Bioscience and \\ Biotechnology, College of Agriculture, University of the Ryukyus, Okinawa 903-01, Japan
}

\begin{abstract}
To compare the atherogenecity of different fats and oils, a total of forty, 40-dayold male Japanese quails were fed one of the following diets for three months: basal diet (control), a diet-containing $15 \%$ corn oil (CO) and $2 \%$ cholesterol (CH), a diet-containing $15 \%$ oleic acid $(\mathrm{OL})$ and $2 \% \mathrm{CH}$, a diet-containing $15 \%$ perilla oil $(\mathrm{PE})$ and $2 \% \mathrm{CH}$, a dietcontaining $15 \%$ primrose oil $(P R)$ and $2 \% \mathrm{CH}$. A higher plasma cholesterol concentration was found in the birds in the $C O$ and $O L$ groups, whereas the PE and PR groups showed a much lower level of plasma cholesterol than the CO and OL groups. In proportion to the increased plasma cholesterol, both $\mathrm{CO}$ and $\mathrm{OL}$ groups showed narrowing of the lumen of the ascending aorta and its large branches due to marked lipid-rich intimal thickening. Ultrastructural changes in the ascending aorta and its large branches were correlated with the degree of intimal thickening. The major foam cell types were macrophages and fibroblastic cells. The PE and PR groups showed the fewest lipid-rich intimal thickening lesions in their ascending aorta and its large branches. These findings suggest that the alpha-linolenic acid contained in perilla oil is less atherogenic than oleic and linoleic acid, and gamma-linolenic acid contained in primrose oil has a tendency to decrease the plasma lipid level.
\end{abstract}

Key words: atherogenecity, Japanese quail, perilla oil, primrose oil

\section{Introduction}

Epidemiological studies have shown that diets rich in saturated fatty acids (SFA) and cholesterol increase the risk of coronary heart disease [1]. Furthermore, numerous studies have reported that polyunsaturated fatty acids (PUFA) cause a greater hypocholesterolemic effect and are less atherogenic than SFA [13, 19, 28].
According to some authors monounsaturated fatty acids (MUFA) have no effect on lowering plasma lipids [10]. It was also reported that MUFA elevated plasma lipids in human [2]. On the other hand, human plasma lipids were decreased by MUFA-rich diets on some occasions [6]. Thus the role of MUFA is still debatable. PUFA such as linoleic, alpha-linolenic and arachidonic acids are considered to be essential for

(Received 17 April 1995 / Accepted 12 September 1995)

Address corresponding: T. Toda, Department of Clinical Laboratory Medicine, University of the Ryukyus, Nishihara-Cho, 207 Aza Uehara, Okinawa 903-01, Japan 
growth and proper nutrition, and they can be synthesized in plants, but not in vertebrates. The effect of alpha-linolenic acid and gamma-linolenic acid on lipid metabolism is not well documented because they are unavailable in pure form. The fatty acid content of different edible oils varies, and the fatty acids in dietary fat influence the plasma lipid level and the development of atherosclerosis. It is therefore essential to evaluate the atherogenecity of dietary fat in both man and animals. Japanese quails have proved to be a convenient and inexpensive experimental animal model due to their small size and lower intake of food [21]. We therefore performed a comparative study on the effects of corn oil which is rich in linoleic acid, the effects of oleic acid which is mainly composed of MUFA, the effects of perilla oil which is rich in alphalinolenic acid, and the effects of primrose oil which is rich in gamma-linolenic acid, on plasma and hepatic lipid levels and aortic atherosclerosis in the Japanese quail.

\section{Materials and Methods}

Forty 40-day-old male Japanese quails (Kyudo Co., Ltd., Kumamoto, Japan) were used in this experiment. They were kept in individual cages in an air-conditioned and light controlled room (temperature $23 \pm 1^{\circ} \mathrm{C}$, relative humidity $55 \pm 10 \%$, ventilation: 15 times per hour, light time: 7.00 a.m. to 7.00 p.m.). They had free access to food and water. The birds were divided into the following 5 groups: Control, a basal-fed group; $\mathrm{CO}$, a corn oil-fed group; OL, an oleic acid-fed group; PE, a perilla oil-fed group; and PR, a primrose oil-fed group. The mean food intake in each group ranged from 14 to $15 \mathrm{~g} / \mathrm{bird} /$ day. In our previous experiment [9], a $2 \%$ cholesterol and $15 \%$ corn oil containing diet produced significant hypercholesterolemia and a higher incidence of atherosclerotic lesions in commercially available quails, but a diet with cholesterol only resulted in mild hypercholesterolemia (Total serum cholesterol: $470.8 \pm$ 85.1 ) and atherosclerotic lesions (Mean intimal thickness: 3 ). Fifteen percent oil or fat and $2 \%$ cholesterol were therefore mixed with the basal mash in the present experiment. The basal mash (Kyoei, Shiryo, Okinawa, Japan) contained $18.3 \%$ protein, $3.8 \%$ fat, $65.8 \%$ carbohydrate, $6.6 \%$ ash, $3.5 \%$ fiber, $0.7 \% \mathrm{Ca}, 0.05 \% \mathrm{P}$, $1.25 \%$ vitamin mix and $2842 \mathrm{Kcal} / \mathrm{Kg}$.
After being fed the test diets for three months, the quails were sacrificed under ether anesthesia. Blood was collected in heparin containing test tubes and was centrifuged to obtain plasma for measuring the lipid levels and fatty acid composition. The entire liver was removed and, after being washed in normal saline, was blotted with a paper towel, weighed and kept frozen to measure the hepatic lipid. The lipid aliquots were extracted from liver by the method of Folch and Sloane-Stanley [4]. Plasma and hepatic cholesterol and triglyceride were measured by the enzymatic method (Determiner LTCM, R 1 and 2 and Determiner LTGM R 1 and 2 Kyowa Medix, Tokyo). The fatty acid composition of the test oils, plasma and liver lipid were analyzed by gas-liquid chromatography as described elsewhere [22].

For the morphological study, the heart along with the ascending aorta and brachiocephalic arteries was removed and fixed in 10\% formalin and embedded in paraffin after proper fixation. Paraffin sections $4 \mathrm{mi}$ crometers thick were made and stained with hematoxylin-eosin (H.E.), Mallory Azan (M.A.) and elastica van Gieson (E.V.) for histologic and histometric examination. As reported previously [24], the maximal intimal thickness of three to four representative large arteries from the histologic sections of each quail was measured with an ocular micrometer. The mean thickness of each group was calculated from the average intimal thickness of arteries in each group. The frequency of intimal thickening (Incidence) was calculated from the percentage of arteries showing intimal thickening among the arteries examined in each group. The severity of atherosclerosis (AI) was expressed as the average degree of intimal thickening of the arteries examined in each group.

For electron microscopy, small pieces of ascending aortic tissue were fixed in $2 \%$ glutaraldehyde, postfixed in $1 \%$ osmium tetroxide, dehydrated in increasing concentrations of alcohol, and embedded in spur resin. Ultrathin sections were stained with uranyl acetate and lead citrate, and were examined with a JEM 2000 EX electron microscope.

Statistical analysis was performed by chi-square test and Duncan's multiple range test. All manipulations were carried out in accordance with the Guidelines for Animal Experimentation of the University of the Ryukyus. 


\section{Results}

\section{Biochemistry}

Table 1 shows the characteristic fatty acid composition of used fat or oil in each experimental group. Corn oil was rich in $\mathrm{n}-6$ family PUFA, linoleic acid as well as oleic acid. Perilla oil contained a greater amount of the n-3 family PUFA, alpha-linolenic acid. On the other hand, primrose oil was rich in linoleic acid, but it also contained an almost equal amount of n-6 family PUFA gamma-linolenic acid, and oleic acid. The plasma lipid profile of the experimental birds is shown in Table 2. The plasma cholesterol level was increased in all the oil-fed groups. The mean plasma cholesterol level was higher among the $\mathrm{CO}, \mathrm{OL}$ and PR groups than that of the PE group, but the PR group tended to show a lower level of plasma lipid than the $\mathrm{CO}$ and $\mathrm{OL}$ groups. The differences among the experimental groups in the mean plasma triglyceride values were not significant. The percentage of plasma esterified cholesterol also showed no significant variation. Body weight was slightly increased in all fat-fed groups, but it was not significantly different. Table 3 shows the effect of the dietary oils on liver weight and hepatic lipid content in each experimental group. The liver weight tended to show an increase in all the oil-fed groups except the PE group. The increase was about two-fold in the $\mathrm{CO}, \mathrm{OL}$ and PR groups in comparison to the control group. The concentration of hepatic lipids was similar to that of the plasma. The hepatic cholesterol level also increased in all the oil-fed groups, but it was significantly higher in the $\mathrm{CO}$ group than the PE group.

Table 4 shows the plasma fatty acid composition of the different groups and it was expressed as the relative percentage of total fatty acids. The fatty acid composition of the plasma in the different groups varied. Linoleic acid was found in large amounts in the plasma in both the CO and PR groups. Alpha-linolenic and gamma-linolenic acids were detected in significantly higher amounts in the PE and PR groups, respectively. The PE and PR groups showed a low concentration of MUFA but the concentration of PUFA was high in their plasma. Although the concentration of MUFA was higher in the $\mathrm{CO}$ and $\mathrm{OL}$ groups, the concentration of PUFA was lower in these groups than in the PE and PR

Table 1. Fatty acid composition of the oil or fat used in each experimental group (as \% of total fatty acids)

\begin{tabular}{lccccccc}
\hline & \multicolumn{9}{c}{ (Fatty acids) } & & & \multicolumn{2}{c}{} \\
& $16: 0$ & $18: 0$ & $18: 1$ & $18: 2$ & $18: 3(\gamma)$ & $18: 3(\alpha)$ & P/S ratio \\
\hline Control & 15.9 & 2.6 & 23.1 & 49.6 & - & 3.6 & 4.1 \\
Corn (CO) & 11.4 & 2.6 & 35.0 & 48.2 & - & - & 3.44 \\
Oleic (OL) & - & - & 94.7 & - & - & - & - \\
Perilla (PE) & 6.2 & 2.2 & 19.8 & 12.9 & - & 56.1 & 8.21 \\
Primrose (PR) & 6.2 & 1.8 & 10.7 & 71.2 & 8.4 & - & 9.95 \\
\hline
\end{tabular}

P/S: Polyunsaturated/Saturated.

Table 2. Plasma lipid concentration of different groups

\begin{tabular}{lcccc}
\hline & $\begin{array}{c}\text { No. of } \\
\text { birds }\end{array}$ & $\begin{array}{c}\text { Triglyceride } \\
(\mathrm{mg} / \mathrm{d} l)\end{array}$ & $\begin{array}{c}\text { Total chol } \\
(\mathrm{mg} / \mathrm{d} l)\end{array}$ & $\begin{array}{c}\text { Ester/Free } \\
\text { chol ratio }\end{array}$ \\
\cline { 4 - 5 } Control & 8 & $99.3 \pm 5.5$ & $218 \pm 12.2^{\mathrm{a}}$ & 2.3 \\
Corn (CO) & 7 & $184.0 \pm 53.8$ & $1624 \pm 406.0^{\mathrm{c}}$ & 3.0 \\
Oleic (OL) & 9 & $117.0 \pm 24.6$ & $1606 \pm 302.0^{\mathrm{c}}$ & 2.9 \\
Perilla (PE) & 8 & $113.0 \pm 27.7$ & $908 \pm 295.0^{\mathrm{b}}$ & 2.6 \\
Primrose (PR) & 8 & $140.0 \pm 32.2$ & $1354 \pm 253.0^{\mathrm{bc}}$ & 2.6 \\
\hline
\end{tabular}

Chol: Cholesterol, Ester: Esterified. Data are expressed as the mean \pm standard error. Different superscript letters show significant difference at $p<0.05$ according to Duncan's multiple range test. 
groups. The concentration of higher metabolites of linoleic acid such as arachidonic acid was higher in the PR group than in all other groups. Eicosapentaenoic and docosahexaenoic acids are the higher metabolites of alpha-linolenic acid. The piasma eicosapentaenoic acid level was higher in the PE group, but the docosahexaenoic acid level was almost the same in the $\mathrm{OL}, \mathrm{PE}$ and PR groups. The percentage of different fatty acids in the liver lipids was almost identical with that of plasma in all groups.

\section{Light Microscopic Observation}

A single layer of flat endothelial cells covered the tunica intima. The tunica media of the ascending aorta had a lamellar structure of elastic fibers and spindle cells. The aorta from quails fed a basal diet revealed only slight intimal thickening (Fig. 1). The oil-fed groups showed lipid-rich intimal thickening lesions, the degree of which was varied. In contrast to the PE and
PR groups, the $\mathrm{CO}$ and OL groups showed marked lipid-rich intimal thickening lesions (Fig. 2). Table 5 shows the frequency of incidence and the severity (AI) of the intimal thickening in each experimental group. The PE and PR groups had a lower incidence and less severe intimal thickening than the $\mathrm{CO}$ and $\mathrm{OL}$ groups.

\section{Electron Microscopic Observation}

The inner layer of the aortic wall contained stellate shaped fibroblastic cells characterized by finger-like extensions of the cytoplasm. The tunica media contained smooth muscle cells as well as fibroblastic cells. The smooth muscle cells were characterized by the presence of abundant myofilaments, peripheral dense bodies and basement membrane (Fig. 3). The proliferating intimal cells in the thickened intima of all oil-fed groups had almost the same features. The subendothelial space was widened due to the accumulation of lipid-containing cells which had kidney-shaped nuclei, but no

Table 3. Liver lipid concentration and liver weight per $100 \mathrm{~g}$ body weight (BW)

\begin{tabular}{lccccc}
\hline & $\begin{array}{c}\text { Triglyceride } \\
(\mathrm{mg} / \mathrm{g} \mathrm{LT})\end{array}$ & $\begin{array}{c}\text { Total chol } \\
(\mathrm{mg} / \mathrm{g} \mathrm{LT})\end{array}$ & $\begin{array}{c}\text { Ester/Free } \\
\text { chol ratio }\end{array}$ & $\begin{array}{c}\text { Liver weight } \\
(\mathrm{g} / 100 \mathrm{~g} \mathrm{BW})\end{array}$ & $\begin{array}{c}\text { Total lipid } \\
\text { (mg/g LT) }\end{array}$ \\
Control & $9.0 \pm 0.3$ & $3.3 \pm 0.4^{\mathrm{a}}$ & 3.0 & $1.3 \pm 0.1$ & $50.4 \pm 2.9^{\mathrm{a}}$ \\
Corn (CO) & $17.2 \pm 6.1$ & $130.0 \pm 6.5^{\mathrm{c}}$ & 3.8 & $2.3 \pm 0.6$ & $260.0 \pm 38.2^{\mathrm{c}}$ \\
Oleic (OL) & $11.9 \pm 2.5$ & $120.0 \pm 8.6^{\mathrm{bc}}$ & 2.9 & $2.9 \pm 0.3$ & $229.0 \pm 346^{\mathrm{b}}$ \\
Perilla (PE) & $34.2 \pm 10.1$ & $83.4 \pm 11.6^{\mathrm{b}}$ & 3.4 & $1.3 \pm 0.2$ & $139.0 \pm 14.0^{\mathrm{ab}}$ \\
Primrose (PR) & $17.5 \pm 3.2$ & $111.0 \pm 9.1^{\mathrm{hc}}$ & 2.8 & $2.4 \pm 0.8$ & $229.0 \pm 34.6^{\mathrm{b}}$ \\
\hline
\end{tabular}

Chol: Cholesterol, Ester: Esterified, LT: Liver tissue. Data are expressed as the mean \pm standard error. Different superscript letters show significant difference at $p<0.05$ according to Duncan's multiple range test.

Table 4. Plasma fatty acid composition (as \% of total fatty acids)

\begin{tabular}{|c|c|c|c|c|c|c|c|c|c|c|c|c|}
\hline & $14: 0$ & $16: 0$ & $16: 1$ & 18:0 & $18: 1$ & $18: 2$ & $18: 3(\gamma)$ & $18: 3(\alpha)$ & $20: 4$ & $20: 5$ & $22: 6$ & UK \\
\hline Control & $0.8 \pm 0.1^{a}$ & $22.0 \pm 3.0^{4}$ & $3.6 \pm 0.3^{a}$ & $14.3 \pm 0.4$ & $23.1 \pm 0.9$ & $19.5 \pm 0.7^{\mathrm{a} d}$ & $0^{a}$ & $0.7 \pm 0.2^{a}$ & $6.5 \pm 1.6^{a}$ & $1.1 \pm 0.2^{4}$ & $6.1 \pm 1.4$ & $0.9 \pm 0.4^{4}$ \\
\hline $\begin{array}{l}\text { Corn } \\
(\mathrm{CO})\end{array}$ & $0.9 \pm 0.2^{a}$ & $11.7 \pm 0.9^{b}$ & $1.9 \pm 0.3^{\mathrm{h}}$ & $11.3 \pm 0.4^{b}$ & $22.0 \pm 1.9^{a}$ & $27.3 \pm 1.9^{\mathrm{b}}$ & $0:$ & $3.3 \pm 0.4^{\mathrm{b}}$ & $9.6 \pm 1.3^{a b}$ & $2.4 \pm 0.5$ & $6.3 \pm 1.5^{3}$ & $2.7 \pm 0.9$ \\
\hline $\begin{array}{l}\text { Oleic } \\
\text { (OL) }\end{array}$ & $1.1 \pm 0.2^{4}$ & $9.6 \pm 0.8^{b}$ & $4.5 \pm 0.2$ & $10.3 \pm 0.2^{b}$ & $23.8 \pm 0.8^{a}$ & $14.0 \pm 0.4$ & $0^{a}$ & $2.9 \pm 0.2^{b}$ & $10.4 \pm 0.5^{\mathrm{b}}$ & $5.6 \pm 0.2$ & $13.5 \pm 0.4^{b}$ & $4.1 \pm 0.4^{\mathrm{bo}}$ \\
\hline $\begin{array}{l}\text { Perilla } \\
\text { (PE) }\end{array}$ & $0.7 \pm 0.2^{\mathrm{i}}$ & $8.8 \pm 0.3^{b}$ & $2.1 \pm 0.2^{\mathrm{b}}$ & $10.7 \pm 0.4^{b}$ & $13.6 \pm 0.5^{\mathrm{h}}$ & $15.8 \pm 0.6$ & $0^{a}$ & $14.2 \pm 0.4$ & $6.1 \pm 0.2^{a}$ & $10.8 \pm 0.4^{d}$ & $11.2 \pm 0.6^{\mathrm{b}}$ & $6.1 \pm 0.8^{c d}$ \\
\hline $\begin{array}{l}\text { Primrose } \\
\text { (PR) }\end{array}$ & $1.0 \pm 0.7^{a}$ & $9.7 \pm 0.2^{b}$ & $1.9 \pm 0.2^{b}$ & $11.2 \pm 0.4^{b}$ & $12.2 \pm 0.4^{\mathrm{b}}$ & $22.4 \pm 0.8^{d}$ & $2.7 \pm 0.2^{b}$ & $1.8 \pm 0.2^{\mathrm{a}}$ & $16.4 \pm 0.6^{c}$ & $2.9 \pm 0.3^{\text {ho }}$ & $10.7 \pm 2.4^{\mathrm{h}}$ & $7.1 \pm 0.6^{\mathrm{d}}$ \\
\hline
\end{tabular}

UK:unknown. Data are expressed as the mean \pm standard error. Different superscript letters show significant difference at p<0.05 according to Duncan's multiple range test. 
basement membrane. Lipid-containing cells in the deeper portion of the thickened intima had the characteristic features of fibroblastic cells such as spindle or elliptical nuclei and abundant organelles, but no basement membrane (Fig. 4).

\section{Discussion}

Japanese quails have been used as a useful model for the study of atherosclerosis due to their high susceptibility to dietary fat and cholesterol [17]. The present experiment confirmed that lipid-rich intimal lesions can be induced in the ascending aorta and its brachiocephalic arteries in the Japanese quail by oral administration of cholesterol and oils or fats.

A seven country study showed that middle aged male Cretans who consumed olive oil which is rich in MUFA had low serum cholesterol and a low incidence of coro-

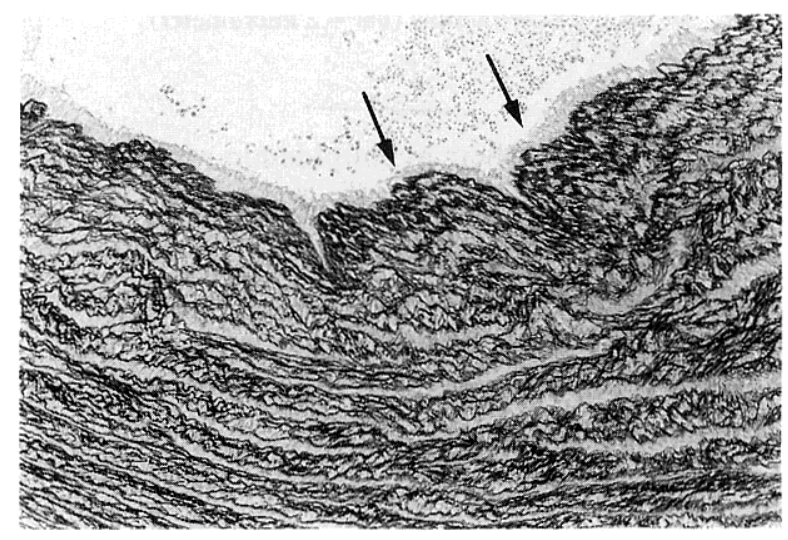

Fig. 1. Slight intimal thickening (arrow) in the ascending aorta of the Control Group (E.V. $\times 100)$. nary heart disease [11]. Grundy [6] also showed that MUFA has lowering effect on serum lipids in comparison to SFA. On the other hand, Chang and Huang [2] have reported that MUFA has no hypocholesterolemic effect, and it increases some fractions of plasma lipids including triglycerides and low density lipoprotein cholesterol in human. Plasma cholesterol in rats was increased after giving them MUFA-rich oil [8]. Plasma cholesterol in African green monkeys fed-MUFA remained intermediate between those of the SFA group and the PUFA group [18]. In our present quail experiment we observed that only MUFA containing oleic acid was more hyperlipidemic and atherogenic than perilla oil. Possibly this may be due to the species difference between man and quail, or the combined effect of cholesterol and MUFA.

Corn oil has been known to be generally less atherogenic than saturated fats. But in the present study

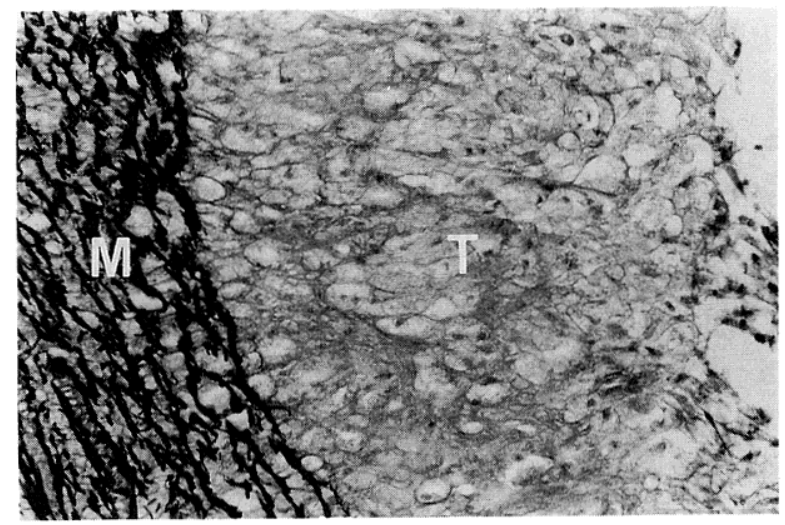

Fig. 2. Extensive lipid deposition is seen in the thickened intima $(\mathrm{T})$ of the ascending aorta in the OL-Group. M: Tunica media (E.V. $\times 200)$.

Table 5. Atherosclerotic index of ascending aorta and its large branches

\begin{tabular}{lcrlc}
\hline & Number of quails & \multicolumn{2}{c}{$\begin{array}{l}\text { Incidence of } \\
\text { thickened intima (IT) }\end{array}$} & $\begin{array}{c}\text { Mean intimal thickness (AI) } \\
\left(\times 10^{-2} \mathrm{~mm}\right)\end{array}$ \\
\hline Control & 8 & $4 / 27$ & $(14.8 \%)^{\mathrm{a}}$ & $0.1 \pm 0.1^{\mathrm{a}}$ \\
Corn (CO) & 7 & $11 / 26$ & $(42.3 \%)^{\mathrm{b}}$ & $9.6 \pm 2.7^{\mathrm{b}}$ \\
Oleic (OL) & 9 & $16 / 34$ & $(47.1 \%)^{\mathrm{b}}$ & $8.4 \pm 2.1^{\mathrm{b}}$ \\
Perilla (PE) & 8 & $9 / 30$ & $(30.0 \%)^{\mathrm{ab}}$ & $2.0 \pm 0.7^{\mathrm{a}}$ \\
Primrose (PR) & 8 & $11 / 31$ & $(35.5 \%)^{\mathrm{ab}}$ & $4.4 \pm 1.3^{\mathrm{ab}}$ \\
\hline
\end{tabular}

Data are expressed as the mean \pm standard error. Statistical significance of difference of IT and AI among groups was performed by chi-square test and Duncan's multiple range test, respectively. Different superscript letters show significant difference at $\mathrm{p}<0.05$. 


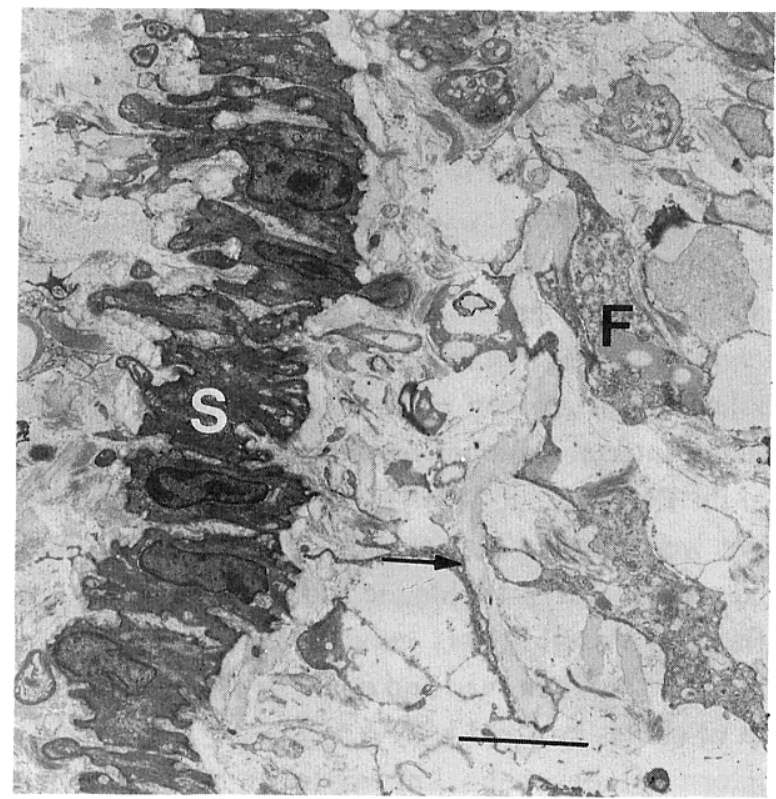

Fig. 3. Note smooth muscle cells(S), fibroblastic cells (F) and elastic fibers (arrow) in the middle portion of the ascending aorta (bar $=5$ micrometer).

we observed that corn oil was hyperlipidemic and atherogenic as well as oleic acid. A hyperlipidemic and atherogenic effect of corn oil on Rhesus monkeys was reported previously [25]. Linoleic acid, a n-6 family PUFA is well known to have a hypocholesterolemic effect $[12,14]$. On the other hand, Wang and Powell [27] found increased amounts of esterified monohydroxy derivatives of linoleic acid and arachidonic acid in the atherosclerotic lesions in the aorta of rabbits, which were fed linoleic acid rich peanut oil. They also proposed that these increased amounts of peroxidized lipids could be involved in the development of atherosclerosis by inhibiting prostanoid synthesis by vascular cells and platelets. Corn oil was rich in linoleic acid, but it also contained oleic acid and SFA. Thus in our present experiment the severe atherogenecity of corn oil can be ascribed to the potential synergistic atherogenic effect of linoleic acid with MUFA and SFA.

Increased dietary intake of polyunsaturated vegetable oils has been reported to lower the plasma concentration of LDL cholesterol [3,20]. When the SFA and MUFA in the diet are replaced by PUFA that are rich in the n-9, n- 6 and particularly the n-3 family of fatty acids, atherosclerosis can be inhibited or preexisting lesions can be reversed [15]. No unified mechanism by

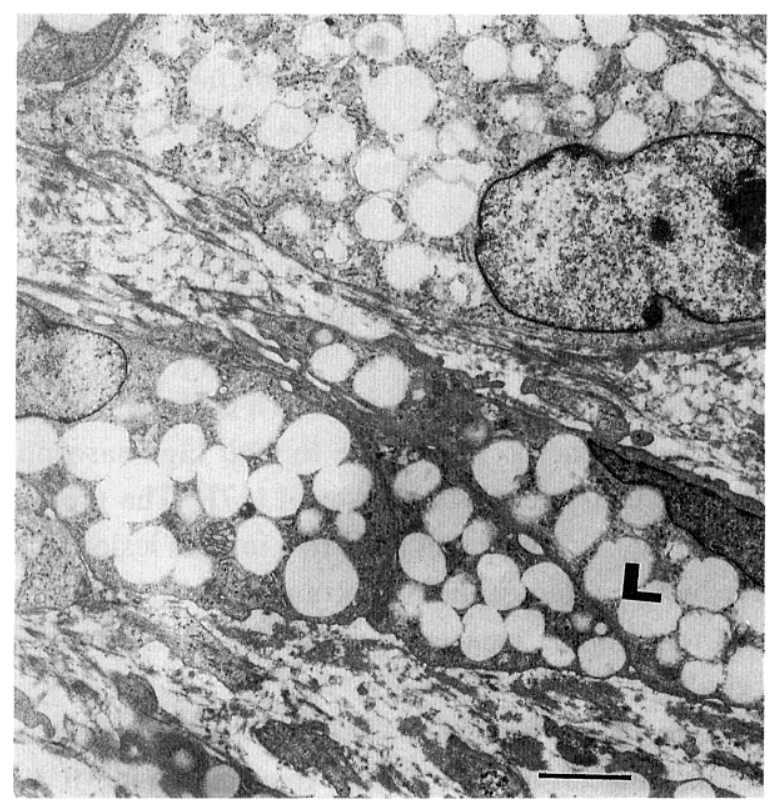

Fig. 4. Spindle-shaped lipid-containing cells (L) without a basement membrane are present in the deeper portion of the thickened intima (bar $=2$ micrometer).

which PUFA exert their hypolipidemic effect has yet been established. Hypothetically PUFA enhance hypolipidemia by decreasing the rate of cholesterol absorption and synthesis, transferring cholesterol from plasma to tissues, changing the ratio of cholesterol to protein in LDL, changing the rates of synthesis or catabolism of individual lipoproteins, and increasing the excretion of neutral and acidic steroids [5].

The fatty acid composition of quail plasma and tissue lipids is significantly influenced by dietary fatty acids [26]. The concentration of alpha-linolenic acid and its higher metabolite eicosapentaenoic acid was significantly higher in the plasma and liver lipid of the PE group than in other groups in our experiment. Hood [7] found that linseed oil and tuna fish oil, both rich in n-3 family PUFA, have a greater hypolipidemic effect in quail than beef drippings containing saturated fat and safflower oil rich in linoleic acid. In another study [16] significant hypolipidemia was observed in chicken by increasing dietary $n-3$ fatty acids and the PUFA SFA $(\mathrm{P} / \mathrm{S})$ ratio in their diet. The $\mathrm{P} / \mathrm{S}$ ratio of perilla oil was high and it contained a higher amount of n-3 family fatty acid, alpha-linolenic acid, and the quails in the PE group showed a lower incidence and less lipidrich atherosclerotic lesions, as well as the PR group. 
Primrose oil contained a large amount of linoleic acid, and it also contained gamma-linolenic acid which was not present in other oils used in our experiment. The concentration of gamma-linolenic acid and arachidonic acid was significantly more increased in the plasma and liver lipids of the birds in the PR group than in the other groups. Although the plasma and hepatic concentration of linoleic acid was similar in the $\mathrm{CO}$ and PR groups, the PR group tended to have a low plasma cholesterol level and less atherosclerotic lesions. The metabolites of linoleic acid such as gamma-linolenic and arachidonic acid appear to be more effective in lowering plasma cholesterol than the parent molecule of linoleic acid [23]. The findings in our study also reflected this. If the amount of gamma-linolenic acid in primrose oil could be increased, a greater antiatherogenic effect might be achieved. As we mentioned earlier, only a cholesterol containing diet could not produce significant hyperlipidemia and atherosclerotic lesions in commercially available quails [9], and we considered that the combined effect of $2 \%$ cholesterol and $15 \%$ of different oils was responsible for the development of atherosclerotic lesions in the present experiment. From the present findings obtained in Japanese quail, we surmise that perilla oil is significantly less atherogenic than oleic acid and corn oil, and primrose oil also had a hypocholesterolemic effect.

\section{Acknowledgment}

We thank Mr. D. Mrozek for critical reading of the manuscript.

\section{References}

1. Berkmin, S.J.D. and Lindberg, H.A. 1977. Risk factors: their role in etiology and pathogenesis of the atherosclerotic disease. pp. 42-119. In: The Pathogenesis of Atheroslerosis (Wissler, R.W., Greer, J.C. eds.), Willium and Wilkins, Baltimore.

2. Chang, N.W. and Huang, P.C. 1990. Effects of dietary monounsaturated fatty acids on plasma lipids in humans. J. Lipid Res. 31: 2141-2147.

3. Connor, W.E., Witiak, D.T., Stone, D.B., and Armstrong, M.L. 1969. Cholesterol balance and fecal neutral steroid and bile acid excreation in normal men fed dietary fats of different fatty acid composition. J. Clin. Invest. 48: 1363 1375.

4. Folch, J.L.M. and Sloane-Stanley, G.H. 1957. A simple method for the isolation and purification of total lipids from animal tissue. J. Biol. Chem. 226: 497-506.

5. Goodnight, S.H., Harris, W.S., Conner, W.E., and Illingworth, D.R. 1982. Polyunsaturated fatty acids, hyperlipidemia, and thrombosis. Arteriosclerosis 2: 87-113.

6. Grundy, S.M. 1989. Monounsaturated fatty acids and cholesterol metabolism: implication for dietary recommendation. J. Nutr. 119: 529-533.

7. Hood, R.L. 1991. Research note: Effect of dietary fats on hepatic cholesterol synthesis in Japanese quails. Poultry Sci. 70: $1848-1850$.

8. Huang, P.C. and Chang, N.W. 1989. Effects of dietary monounsaturated fatty acids on serum and liver lipids in rats. Proceedings of the 14th International Conference of Nutrition. p. 878.

9. Inoue, Y., Toda, T., Igawa, T., Tani, T., and Kimura, Y. 1995. The response of serum and hepatic lipids and aortic wall to different level of dietary cholesterol: A comparative study between hyperlipidemia-and- atherosclerosis-prone quail and commercially available quail. Tohoku J. Exp. Med. 175: 1-13.

10. Keys, A., Anderson, J.T., and Grande, F. 1965. Serum Cholesterol response to changes in diet. Metabolism 14: 747-787.

11. Keys, A. 1970. Coronary heart disease in seven countries. Circulation (Suppl 1) 41: 1-211.

12. Lee, J.H., Ikeda, I., and Sugano, M. 1992. Effects of dietary $n-6 / n-3$ polyunsaturated fatty acid balance on tissue lipid levels, fatty acid patterns, and eicosanoid production in rats. Nutrition 8: 162-166.

13. Mahley, R.W. 1981. The role of dietary fat and cholesterol in atherosclerosis and lipoprotein metabolism. West. J. Med. 134: 34-42.

14. Ney, D.K., Lasekan, J.B., and Kim, J. 1989. Relative effects of dietary oleic-and linoleic-rich oils on plasma lipoprotein composition in rats. J. Nutr. 119: 857-863.

15. Nordoy, A. and Goognight, S.H. 1990. Dietary lipids and Thrombosis, Relationships to atherosclerosis. Arteriosclerosis 10: 149-163.

16. Phetteplace, H.W. and Watkins, B.A. 1990. Lipid measurements in chickens fed different combinations of chicken fat and menhaden oil. J. Agric. Food Chem. 38: 1848-1853.

17. Radcliffe, J.D. and Liebsch, K.S. 1985. Dietary induction of hypercholesterolemia and atherosclerosis in Japanese quail of strain SEA. J. Nutr. 115: 1154-1161.

18. Rudel, L.L., Haines, J.L., and Sawyer, J.K. 1990. Effects on plasma lipoproteins of monounsaturated, saturated, and polyunsaturated fatty acids in the diet of African green monkeys. J. Lipid Res. 31: 1873-1882.

19. Schonfeld, G., Patsch, W., Rudel, L.L., Nelson, C., Epstein, M., and Olson, R.E. 1982. Effect of dietary cholesterol and fatty acids on plasma lipoprotein. J. Clin. Investig. 69: 1072-1080.

20. Shepherd, J., Packard, C.J., Grundy, S.M., Yeshurun, D., Gotto, A.M., and Taunton, O.D. 1980. Effects of saturated and polyunsaturated fat diets on the chemical composition 
and metabolism of low density lipoprotein in man. J. lipid Res. 21: 91-99.

21. Smith, R.L. and Hilker, D.M. 1973. Experimental dietary production of aortic atherosclerosis in Japanese quail. Atherosclerosis 17: 63-70.

22. Sugano, M., Watanabe, M., Kohno, M., Cho, Y.J., and Ide, T. 1983. Effects of dietary trans-fats on biliary and fecal steroid excretion and serum lipoproteins in rats. Lipids 18 : 357-381.

23. Sugano, M. and Ikeda, I. 1991. Frontiers in lipid research: Impact on lipid metabolism. Proceedings 6th Asian Congress of Nutrition. pp. 220-226.

24. Toda, T. and Oku, H. 1995. Effect of medium-chain fatty acids on cholesterolemia and atherosclerosis in Japanese quail. Nutr. Res. 15: 99-113.
25. Vesselinovitch, D., Getz, G.S., Hughes, R.H., and Wissler, R.W. 1974. Atherosclerosis in the Rhesus monkey fed three fats. Atherosclerosis 20: 303-321.

26. Villchez, C., Touchburn, S.P., Chavez, E.R., and Chan, C.W. 1991. Effect of feeding palmitic, oleic, and linoleic acids to Japanese quail hens (Coturnix coturnix japonica). Poultry Sci. 70: 2484-2493.

27. Wang, T. and Powell, W.S. 1991. Increased levels of monohydroxy metabolites of arachidonic acid and linoleic acid in LDL and aorta from atherosclerotic rabbits. Biochem. Biophy. Acta. 1084: 129-138.

28. Zollner, N. and Tato, F. 1992. Fatty acid composition of the diet: impact on serum lipids and atherosclerosis. Clin. Investig. 70: 968-1009. 